resenha

\title{
Professor pedagogo \\ ou professor e pedagogo?
}

Alessandra Raimundo Capusso Eliane Tassi dos Santos

Professoras da rede municipal de Vinhedo

\section{Libâneo, J. C. Pedagogia e Pedagogos, para quê? 10 ed. São Paulo: Cortez, 2008.}

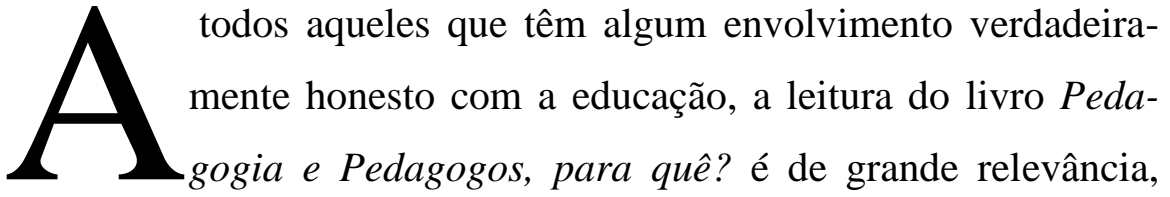
pois o autor se coloca de maneira clara e objetiva, discorrendo sobre temas e questões que nos acompanham e nos incomodam. E aqueles que não se vêem incomodados, não acreditamos seja simplesmente porque não se interessam, mas porque não têm consciência da seriedade da problemática levantada. Fato que faz a leitura deste livro se tornar ainda mais relevante.

Como o próprio título do livro sugere, estamos diante de dúvidas e dilemas envolvendo a especificidade e função da Pedagogia e dos profissionais desta área: os pedagogos. Sendo assim, primeiramente, é necessário nos situarmos e partirmos da única certeza que temos até o momento: pedagogos são os profissionais formados em nível superior nos cursos de Pedagogia. Porém, infelizmente, o que é a Pedagogia, qual sua finalidade e especificidade, não é consenso e não está claro nem mesmo aos próprios pedagogos.

De acordo com o que o livro coloca muito bem, e podemos constatar, por exemplo, observando a própria realidade que cerca as universidades e ambientes escolares, a maioria dos profissionais que se formam em Pedagogia têm a visão disseminada no senso comum: Pedagogia é apenas a formação inicial, em nível superior, para docentes da Educação Infantil e séries iniciais do Ensino Fundamental. Quando muito, também para especialistas da Educação: Orientadores Pedagógicos, Coordenadores Pedagógicos, ViceDiretores de Unidades Escolares, Diretores de Escolas, Supervisores de Ensino e outros. 
resenha

Para o senso comum, não se fala, não se pensa e não se cogita a formação de pedagogos voltados para a área teórica da Educação, para pesquisas; para o pensar a educação. No entanto, que esta seja a visão do senso comum e de leigos é compreensível - não aceitável, mas compreensível mas é, no mínimo, preocupante constatar que essa idéia vem sendo disseminada com tamanha facilidade e competência também no contexto da própria área educacional.

Essa preocupação aumenta paulatinamente, mas muito intensamente, quanto mais refletimos e analisamos a situação. Pois, quando olhamos para essa situação e buscamos explicações para além dos "achismos", encontramos indícios de que "nada é por acaso", e conforme nos aprofundamos, embasados em pesquisas e bibliografias desenvolvidas sob critérios sérios e científicos, vamos construindo uma rede de conhecimento que, ao mesmo tempo que nos liberta da escuridão da ignorância, nos assusta, tamanha é a astúcia e competência do sistema neoliberal que nos envolve.

É preciso, então, começarmos a desconfiar das situações postas, das explicações dadas e da ordem pré-estabelecida, para então começarmos a desvendar as "armadilhas" e "armas" com que o sistema neoliberal, citado acima, tenta nos enredar.

Pedagogia, ciência da educação para a educação

No decorrer do livro o autor se coloca de maneira a defender que a Pedagogia tem um campo de estudos com identidade e problemática próprias. Ela estuda os atos da educação e para isso busca também conhecimentos em outras áreas. Pois, embora seja uma ciência no conjunto das Ciências da Educação, afasta-se das demais para garantir a unidade e sentido das contribuições destas ao fenômeno educativo, dando assim um enfoque globalizante a esse fenômeno, ao mesmo tempo que unitário.

Portanto, a Pedagogia é uma ciência da ação, como a Ética e a Política, mas não uma ciência prática como a Medicina e o Direito, conforme expôs Schimied-Kowarzik (1983). É a área do conhecimento que investiga a realidade educativa no geral e no particular e que para isso busca conheci- 
resenha

mentos, por exemplo, na Psicologia da Educação, na Sociologia da Educação e na Filosofia da Educação - sendo que estas contribuições à Pedagogia é a única razão de existência destas ciências, uma vez que o olhar que elas têm sobre a Educação é compartimentado e não pode dar conta de explicar a problemática que a envolve e todas as suas vicissitudes, ou seja, esta é a especificidade da Pedagogia.

Porém, conforme o próprio autor coloca e podemos presenciar cotidianamente, não há um consenso sobre estas questões, pois o senso comum e muitos pedagogos veem a Pedagogia apenas como o modo de ensinar e as técnicas de ensinar, ou seja, o metodológico, e procedimental.

Mas essa situação de dualidade, de falta de consenso, não é inata à sociedade, a-histórica. Ela vem acompanhando toda a trajetória do desenvolvimento da Educação, no Brasil inclusive, conforme o autor explicita no capítulo IV, onde faz um "esboço histórico e buscas de identidade epistemológica e profissional”.

Parece-nos que essa dualidade é na verdade sintoma do substancioso conflito de interesses e ideologias pelo qual as sociedades modernas e contemporâneas vêm passando. Conflito esse que tem a educação e as escolas como "aparelhos ideológicos do Estado", conforme já exposto, por exemplo, por Saviani (1997) em Escola e Democracia quando expõe a "teoria da escola enquanto aparelho ideológico do Estado", e por Faria (2005) em Ideologia do livro Didático.

É preciso sempre ter clareza de que falamos de escolas e educação localizadas e fazendo parte de uma sociedade neoliberal-capitalista, com suas ideologias e seus ideais estruturados sobre os princípios liberais.

E quem também vem contribuir para que se compreenda esse contexto, de maneira bastante relevante, é Torres (1996) quando fala das estratégias do Banco Mundial para "melhorar” a qualidade da Educação Básica.

Além das dualidades quanto à especificidade da Pedagogia, a educação enfrenta outras tantas, tais como as que se referem à pedagogização generalizada em que encontra a sociedade, conforme cita o autor, principalmente no capítulo V, quando fala da "sociedade pedagógica", das "vicissitudes e impasses atuais da Pedagogia" e das "crises da Pedagogia". Pois, a 
resenha

todo momento, somos bombardeados com programas e materiais das mais diversas mídias enfocando os mais diversos assuntos e vendendo a promessa de apoio pedagógico para a educação de nossas crianças e educandos, ao mesmo tempo em que presenciamos um explicito e abundante interesse e preocupação da mídia, dos meios de comunicação e de profissionais das mais diversas áreas em falar sobre a educação escolar, colocando em xeque sua qualidade, competência e sua eficiência. Muitas vezes, inclusive, usando tom de sarcasmo e ironia, como vimos na edição de 22/05/2009 do Jornal Nacional da Rede Globo de Televisão, com a matéria sobre as decisões tomadas no município de Mirassol/SP em relação às excessivas faltas às escolas dos alunos da rede pública municipal, e nas repetidas matérias da Revista Veja, como as da edição 2047, de 13/02/2008: a entrevista da ex-secretária da Educação do Estado de São Paulo, a Profa. Dra. Maria Helena Guimarães de Castro ("Premiar o Mérito"), e artigos dos economistas Cláudio de Moura Castro e Gustavo Ioschpe, falando sobre "Salário de Professor" e "Pelo direito à ruindade", respectivamente.

Ironicamente, quanto mais se fala na qualidade da educação, menos a vemos, assim como, quanto mais pedagógica a sociedade, menos valor se dá à Pedagogia como ciência.

A prática pedagógica está disseminada na sociedade, o que não poderia ser diferente, uma vez que a Pedagogia pensa $a$, para e sobre a Educação e esta, por sua vez, não se restringe apenas à prática docente e escolar, mas permeia todo o desenvolvimento social e humano, ou seja, conforme diz o autor e outros (alguns, inclusive, citados por ele), até mesmo nas práticas informais, não-intencionais, não-institucionalizadas, há Educação, há formação humana, formação de caráter, identidade e valores.

Se existe uma Educação, existe uma pedagogia para ela, como por exemplo: a educação familiar, a educação religiosa, a educação escolar, a educação dos movimentos sociais... E enquanto a sociedade precisar de Educação, será necessária uma pedagogia. Porém, nos atemos, com especial interesse e preocupação, à Educação explicitamente intencional, a qual exige uma Pedagogia embasada na cientificidade, não negando a influência e interferência das ditas não-intencionais e não-institucionalizadas, pois, “com 
resenha

efeito, a educação informal perpassa as modalidades de educação formal e não-formal”. (Libâneo, 2008 p. 91)

Nos atemos à educação intencional e julgamos urgente a conscientização de pedagogos e professores da necessidade de resgatarem os créditos, valores e importância da Pedagogia; julgamos imprescindível que estes profissionais façam coro a "outra reforma" citada por Vera Maria Candau e reajam contra os acenos do triste "adeus à escola pública", conforme assinalou Gentili (1995); que reajam contra os índices alarmantes da qualidade do ensino e da educação; reajam contra a alienação que nos atrela a uma situação de desprofissionalização, de descaso e desvalorização por parte das sociedades e de seus governos; reajam contra a "má propaganda" que insistem em fazer de seu trabalho, de sua competência, de seus valores e de seus ideais.

Mas, para isso é preciso que, primeiramente, tenham consciência do imenso valor das contribuições da Pedagogia e do pedagogo stricto sensu, conforme defende José Carlos Libâneo.

Do senso comum a uma visão crítico-científica

Agora que já se pode visualizar a idéia de que a Pedagogia é a Ciência da Educação para a Educação, a qual que estuda, investiga e busca entender o fenômeno da Educação de maneira globalizante e particular, nada mais óbvio que visualizar o pedagogo como o profissional que vem atuar nas várias instâncias da prática educativa ligadas, direta ou indiretamente, à organização e processos da Educação, assim como aos modos de ação, com vistas aos objetivos da formação humana previamente definidos histórica e socialmente, ou aquele que, justamente, pensará contra essa pré-definição, uma vez que sua formação técnica e científica deve lhe dar conhecimentos e subsídios para isso.

Esta é a visão que vemos defendida na obra de José Carlos Libâneo (2008) e com a qual concordamos, mas a realidade que cerca e permeia a área educacional está longe de apresentar um consenso sobre a identidade profissional dos pedagogos, assim como sobre a especificidade da Pedago- 
resenha

gia. Aliás, em relação à pedagogização da sociedade, já citada anteriormente, acreditamos que seja uma das maneiras de desmerecer e desvalorizar a necessidade da Pedagogia e de seus profissionais, visto que uma das intenções é justamente não levar a um raciocínio crítico, ou melhor se "vende" a idéia do "desenvolvimento intelectual”, mas este não está relacionado com criticidade, no máximo com uma pseudocriticidade. O que é muito perigoso, pois, cada vez mais, é exatamente esta a situação que presenciamos. Caro leitor, tome cuidado! Por mais contraditório que possa parecer, "quando todos estão pensando a mesma coisa é porque ninguém esta pensando", como diz o provérbio citado pelo jornalista Walter Lippemann.

E isso nos remete novamente a Pedagogia e Pedagogos, para quê?, quando o autor defende a idéia da necessidade de um curso de Pedagogia que forme pedagogos stricto sensu, profissionais voltados e habilitados para a investigação teórica e científica, separadamente de um curso de Pedagogia lato sensu, que se voltaria a formar os docentes da Educação Infantil e Ensino Fundamental I. E, talvez, a criação do curso Normal Superior tenha sido uma resposta a reivindicações como estas. Pois teria sido este o curso destinado à formação de docentes, deixando à Pedagogia a formação de teóricos e pesquisadores? Mas, se assim for, o que pudemos presenciar, na verdade, foi o discurso sério, consciente e científico de um educador comprometido ser tomado pelo sistema e pelo mercado, ressignificado conforme seus interesses e devolvido à sociedade em forma de um curso de formação de professores com qualidade bastante questionável, mas sob a justificativa de que os próprios educadores o pediram.

Quando falamos na má qualidade do Normal Superior, nos referimos principalmente à questão de ser voltado à prática docente, porém separada da teoria científica, isso nos baseando principalmente nos relatos de formandos deste curso, com quem convivemos.

Mas, embora esse curso tenha tido vida curta e já tenha sido extinto, a Educação não teve resolvidos seus problemas e dilemas; ao contrário, encontra-se sem função, rumo e destinos certos. A Pedagogia não deve formar um profissional exclusivamente para a prática docente, mas também não dá conta de formar profissionais voltados para a prática teórica e investigativa. 
resenha

Vive-se um meio-termo que desqualifica a função e profissão de pedagogos e professores.

Embasadas nas leituras que já citamos e em discussões em sala de aula com o professor Sánchez Gamboa (primeiro semestre de 2009), defendemos a idéia de que por trás das críticas e ofensivas dirigidas à Pedagogia e seus profissionais está um emaranhado de ideologias e ideais do mercado e sistema neoliberal-capitalista que veem a Educação brasileira - e sulamericana como um todo - como um grande e promissor campo a ser explorado. Discussão esta na qual não nos aprofundaremos no momento, mas deixamos aqui nossa sugestão.

Para que não ocorram equívocos e não se tenha a impressão errônea de que o autor defende que seja desnecessária a formação teórica dos professores da Educação Infantil e das séries iniciais do Ensino Fundamental, é preciso ser dito que esta é sim imprescindível e que justamente essa falta contribui para a desvalorização de que vimos falando. Conforme o autor cita várias vezes, a falta de conscientização dos professores e pedagogos é também um dos motivos do desprestígio destas profissões:

É uma estranha conduta: o profissional denuncia sua própria tarefa, faz uma gozação de si próprio, mina a instituição e denigre seu próprio trabalho. Está aí mais uma contribuição para o enfraquecimento do prestígio da atividade profissional do educador. (Libâneo, 2008 p. 172)

O que se resume em uma falta de "massa crítica" nesta área, e a questão, também conforme cita o autor, é a distância entre a prática e a teoria, pois “os que 'praticam' a educação estão distantes da discussão teórica e mais interessados no "como fazer"' (ibidem, p. 107).

É preciso que os educadores sejam capazes de enfrentar e recusar as críticas que recebem e questionem o contexto que os cerca. Por exemplo, quando se ouve profissionais da rede municipal de Educação da Prefeitura de São Paulo falando, euforicamente, sobre a intenção e possibilidade da abertura de concurso público para o cargo de picopedagogos, seria necessário também ouvi-los questionando: pr que picopedagogos e não também 
resenha

pedagogos? Não seria porque os psicopedagogos se preocupam com as dificuldades de aprendizagem dos educandos (aprendizagem do que já está préestabelecido), enquanto que os pedagogos devem se preocupar com a Educação como um todo, inclusive com suas finalidades?

Por fim, chega-se à conclusão de que a Educação precisa de pedagogos e de professores pedagogos, e cada um ciente de sua especificidade e da relevância de sua função, combatendo assim a situação que, já na capa, o livro Pedagogia e Pedagogos, para quê? denuncia.

\section{Considerações finais}

Caro leitor, esperamos que ao fim desta leitura você sinta-se instigado a ler o livro Pedagogia e Pedagogos, para quê? Sobretudo, o principal objetivo que desejamos ter atingido é termos despertado, se não sua consciência, ao menos sua curiosidade sobre o que é e para o que serve a Pedagogia.

Porém, desejamos que você venha a fazer essa leitura não apenas para que saiba mais sobre sua possível profissão, mas porque este conhecimento lhe trará novas possibilidades. Pois o conhecimento se transforma em empecilho, talvez pequeno mas um empecilho, para a livre manipulação que o sistema neoliberal-capitalista visa exercer sobre nós. É apenas a partir do conhecimento que nos tornamos menos alienados, menos influenciáveis e controlados por este sistema que se articula de maneira incrivelmente astuta e audaz para nos manipular e inculcar em nós sua ideologia e valores.

Se você é um profissional formado em Pedagogia, e se via obrigado a exercer a docência, esperamos que após estas leituras tenha entendido que não deve se sentir culpado se, depois de ter se formado, tenha percebido que não é isso que realmente quer, porque, ao contrário do que querem que acreditemos, "todo trabalho docente é trabalho pedagógico, mas nem todo trabalho pedagógico é trabalho docente" (Libâneo, 2008, p. 39) - já que o trabalho docente é a forma peculiar do trabalho pedagógico em sala de aula, mas, para o trabalho pedagógico, há um amplo leque de práticas educativas sobre e para a Educação além da sala de aula. 
resenha

E mais que isso, a Educação está carente de bons pedagogos, de profissionais que cumpram com a especificidade do pedagógico: investigar e pensar a Educação e para a Educação, com base, inclusive, nas contribuições de outras ciências, tais como: Psicologia, Filosofia, Sociologia, História, Antropologia...

\section{Referências}

FARIA, Ana Lucia G. de. Ideologia no livro didático. 15 ed. São Paulo: Cortez, 2005. (Coleção Questões da Nossa Época, v. 37).

FREITAS, Helena Costa Lopes. Formação de professores no Brasil: 10 anos de embates entre projetos de formação. In: Educação e Sociedade. Campinas/SP, v. $23, n^{0} 80$, setembro/2002, p.137-168.

. Certificação docente e formação do educador: regulação e desprofissionalização. In: Cadernos Cedes, vol. 24, n. 85, janeiro/2004. Disponível em: www.cedes.unicamp.br> acesso em 10 junho de 2006.

GENTILI, Pablo (org.). Pedagogia da exclusão - crítica ao neoliberalismo em educação. Petrópolis/RJ: Ed. Vozes, 1995.

SANTOS, Lucíola Licinio de C. P. Formação de professores na cultura do desempenho. In: Caderno Cedes. Globalização e Educação: Precarização do Trabalho Docente - II, vol. 26 , n. 89 , novembro/24. Disponível em www.cedes.unicamp.br> acesso em 10 junho de 2006.

SAVIANI, Dermeval, Escola e democracia: teorias da educação, curvatura da vara e onze teses sobre Educação e Política. 31 ed. Campinas/SP: Ed. Autores Associados, 1997. (Coleção Polêmicas do Nosso Tempo, v. 5).

SCHIMIED-KOWARSKY, W. Pedagogia Dialética: de Aristóteles a Paulo Freire. São Paulo: Brasilense, 1983.

TORRES, Rosa Maria. Melhorar a qualidade da educação básica? As estratégias do Banco Mundial. In: HADAD, Sérgio; WARDE, Miriam Jorge; TOMMASI, Lívia de (orgs.). O Banco Mundial e as Politicas Educacionais, São Paulo: Cortez Editora, 1996. p. 125-186.

VASCONCELLOS, C. S. Para onde vai o professor? Resgate do professor como sujeito de transformação. 10 ed. São Paulo: Libertad, 2005. 